\title{
SEEDS
}

Surrey Energy Economics

SURREY

Discussion paper Series

ENERGY

ECONOMICS

Centre

\section{Turkish Aggregate Electricity Demand: An Outlook to 2020}

\author{
Zafer Dilaver and Lester C Hunt
}

May 2011

SEEDS 132

ISSN 1749-8384
Department of Economics University of Surrey 
The Surrey Energy Economics Centre (SEEC) consists of members of the Department of Economics who work on energy economics, environmental economics and regulation. The Department of Economics has a long-standing tradition of energy economics research from its early origins under the leadership of Professor Colin Robinson. This was consolidated in 1983 when the University established SEEC, with Colin as the Director; to study the economics of energy and energy markets.

SEEC undertakes original energy economics research and since being established it has conducted research across the whole spectrum of energy economics, including the international oil market, North Sea oil \& gas, UK \& international coal, gas privatisation \& regulation, electricity privatisation \& regulation, measurement of efficiency in energy industries, energy \& development, energy demand modelling \& forecasting, and energy \& the environment.

SEEC research output includes SEEDS - Surrey Energy Economic Discussion paper Series (details at www.seec.surrey.ac.uk/Research/SEEDS.htm) as well as a range of other academic papers, books and monographs. SEEC also runs workshops and conferences that bring together academics and practitioners to explore and discuss the important energy issues of the day.

SEEC also attracts a large proportion of the department's PhD students and oversees the MSc in Energy Economics \& Policy. Many students have successfully completed their MSc and/or PhD in energy economics and gone on to very interesting and rewarding careers, both in academia and the energy industry.

Enquiries:

Director of SEEC and Editor of SEEDS:

Lester C Hunt

SEEC,

Department of Economics, University of Surrey, Guildford GU2 7XH, UK.

Tel: $\quad$ +44 (0)1483 686956

Fax: $\quad$ +44 (0)1483689548

Email: L.Hunt@surrey.ac.uk

www.seec.surrey.ac.uk 


\section{Surrey Energy Economics Centre (SEEC) Department of Economics University of Surrey}

SEEDS 132

ISSN 1749-8384

\section{TURKISH AGGREGATE ELECTRICITY DEMAND:} AN OUTLOOK TO 2020

Zafer Dilaver and Lester C Hunt

May 2011 


\begin{abstract}
This paper investigates the relationship between Turkish aggregate electricity consumption, GDP and electricity prices in order to forecast future Turkish aggregate electricity demand. To achieve this, an aggregate electricity demand function for Turkey is estimated by applying the structural time series technique to annual data over the period 1960 to 2008. The results suggest that GDP, electricity prices and an underlying energy demand trend (UEDT) are all important drivers of Turkish electricity demand. The estimated income and price elasticities are found to be 0.17 and -0.11 respectively with the estimated UEDT found to be generally upward sloping (electricity using) but at a generally decreasing rate. Based on the estimated equation, and different forecast assumptions, it is predicted that Turkish aggregate electricity demand will be somewhere between 259 TWh and 368 TWh in 2020.
\end{abstract}

JEL Classifications: C22; Q41; Q47; Q48.

Key Words: Turkish Aggregate Electricity Demand; Structural Time Series Model (STSM); Energy Demand Modelling and Future Scenarios. 


\section{Turkish Aggregate Electricity Demand: An Outlook to 2020*}

\author{
Zafer Dilaver\# \\ Surrey Energy Economics Centre (SEEC) \\ Department of Economics \\ University of Surrey, UK \\ and
}

The Republic of Turkey Prime Ministry

PK 06573, Ankara, Turkey.

\author{
Lester C Hunt \\ Surrey Energy Economics Centre (SEEC) \\ Department of Economics \\ University of Surrey, UK
}

\section{Introduction}

The paper investigates the relationship between Turkish aggregate electricity consumption, GDP, average real electricity prices, and an Underlying Energy Demand Trend (UEDT) in order to produce forecast scenarios. An aggregate Turkish electricity demand function is estimated using the structural time series technique with annual data over the period 1960 to 2008. During this period, aggregate Turkish electricity consumption increased by an average of $9.4 \%$ per year from $2.1 \mathrm{TWh}$ to $159.4 \mathrm{TWh}$ [1]. Over the same period real Turkish electricty prices decreased by an average of $0.6 \%$ per annum with electricity prices controlled by successive Turkish governments over the 1960 to 2008 period [2]. This is despite the Turkish 2001 Electricity Market Law No. 4628 towards the end of the period, aimed at creating a liberalized market structure. GDP increased on average by about per $5 \%$ annum over the period from just over 63 (2005 constant YTL) to just below 717 billion YTL (2005 constant YTL). The growth in all three series are illustrated in Figure 1.

\footnotetext{
* Acknowledgements

An earlier version of this study was presented at the 8th Young Energy Engineers and Economists Seminar (YEEES), University of Cambridge April 2010 and we would like to thank Helena Meier and David Cerutti for their constructive comments.

${ }^{\#}$ Corresponding Author. Tel: +44 (0)1483 686956; Fax: +44 (0)1483 689548, E-mail: Z.Dilaver@surrey.ac.uk (Z. Dilaver).
} 
Figure 1: Annual Change in Turkish Aggregate Electricity Consumption, Real AverageElecticity Prices and Real GDP over the period 1960 to 2008

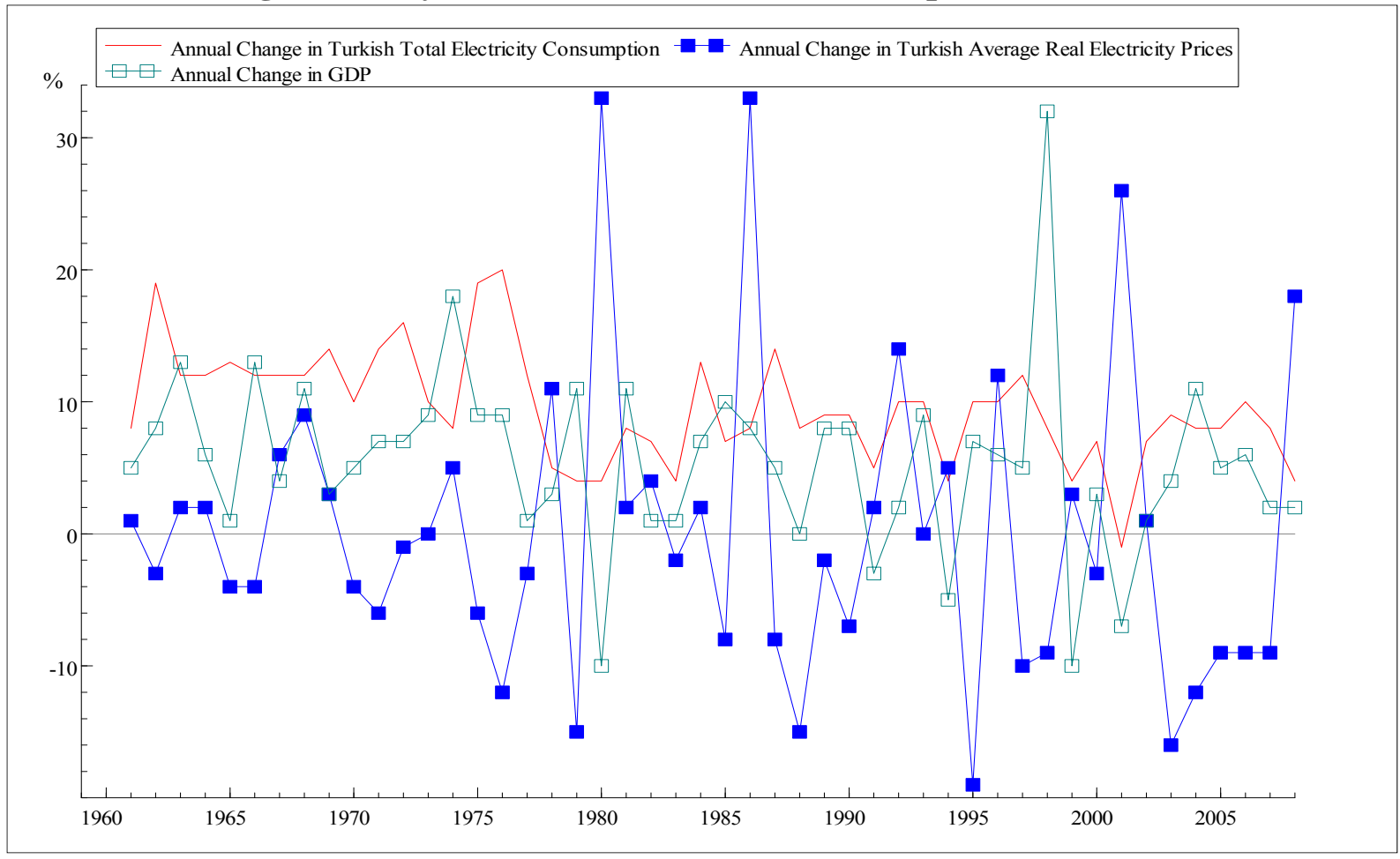

Previous studies that attempted to forecast future Turkish electricity demand are discussed in detail below, but in general they were not very succesful. However, they did not model the UEDT to capture the impact of exogenous effects on Turkish electricty demand, which, is possibly one reason for this apprant lack of success. Given this, the Structural Time Series Model (STSM) is the adopted methodology for estimation used in this research. This allows for the estimation of a stochastic UEDT, which should improve future predictions and provide Turkish policy makers with important information to underpin Turkey's future sustainable economic developement policies. The aim of this study therefore is to investigate how the STSM performs in terms of modelling Turkish aggregate electricity demand thus estimating the key income and price elasticities and the UEDT, which are used to produce various future forecast scenarios for Turkish aggregate electricity demand. 
The next section discusses previous Turkish electricity demand studies followed by Section 3 that outlines the methodology used in this study. Section 4 describes the data used for the analysis and the estimated results followed by Section 5 that presents the forecast scenarios. The final section summarises and concludes.

\section{Previous Turkish Electricity Demand Studies}

A number of early Turkish electricity demand studies were undertaken by governmental institutions, such as the State Planning Organization (SPO), the State Institute of Statistics (SIS) and the Ministry of Energy and Natural Resources (MENR). These tended to use different approaches and models, but all with the general aim of providing energy and electricity planning tools for policy makers in order to sustain economic growth [3]. ${ }^{1}$ However, the predictions from these models have proved to be somewhat different from the actual outcome; one possible explanation being that the models utilised were not sufficient in terms of estimating and understanding Turkish electricity demand. Figure 2 compares the outturn for the years 2004 thru 2008 with the MENR official forecasts produced in 2002 clearly demonstrating their tendency to 'over forecast' [4].

According to Keleş [5] this resulted in the Turkish government attempting to meet these 'overstated' electricity demand forecasts with short term solutions such as the installation of natural gas fuelled power plants - rather than implementing long-term sustainable solutions. As a result, the share of natural gas in power generation increased substantially from the early 1990s - reaching 48\% by 2008, as illustrated in Figure 3 [1]. Moreover, Keleş [5] argues that, not surprisingly, this resulted in a considerable proportion of idle electricity generation

\footnotetext{
${ }^{1}$ A more detailed review of these studies can be found in Ediger and Talidil [3].
} 
capacity, the ineffective use of public funds, the prevention of energy markets being liberalized, and an increased dependency on imported primary energy sources. Consequently, Turkey became increasingly more dependent on imported natural gas, making it vulnerable to natural gas price volatility. Given this, a key motivation for this paper is to estimate Turkish aggregate electricity demand elasticities and the UEDT in order to develop a more robust model and use it to produce more reliable future forecast scenarios for Turkish aggregate electricity demand.

Figure 2: Comparison of the 2002 MENR predictions for Annual Aggregate Electricity Demand Forecasts with Outturn for 2004-2008

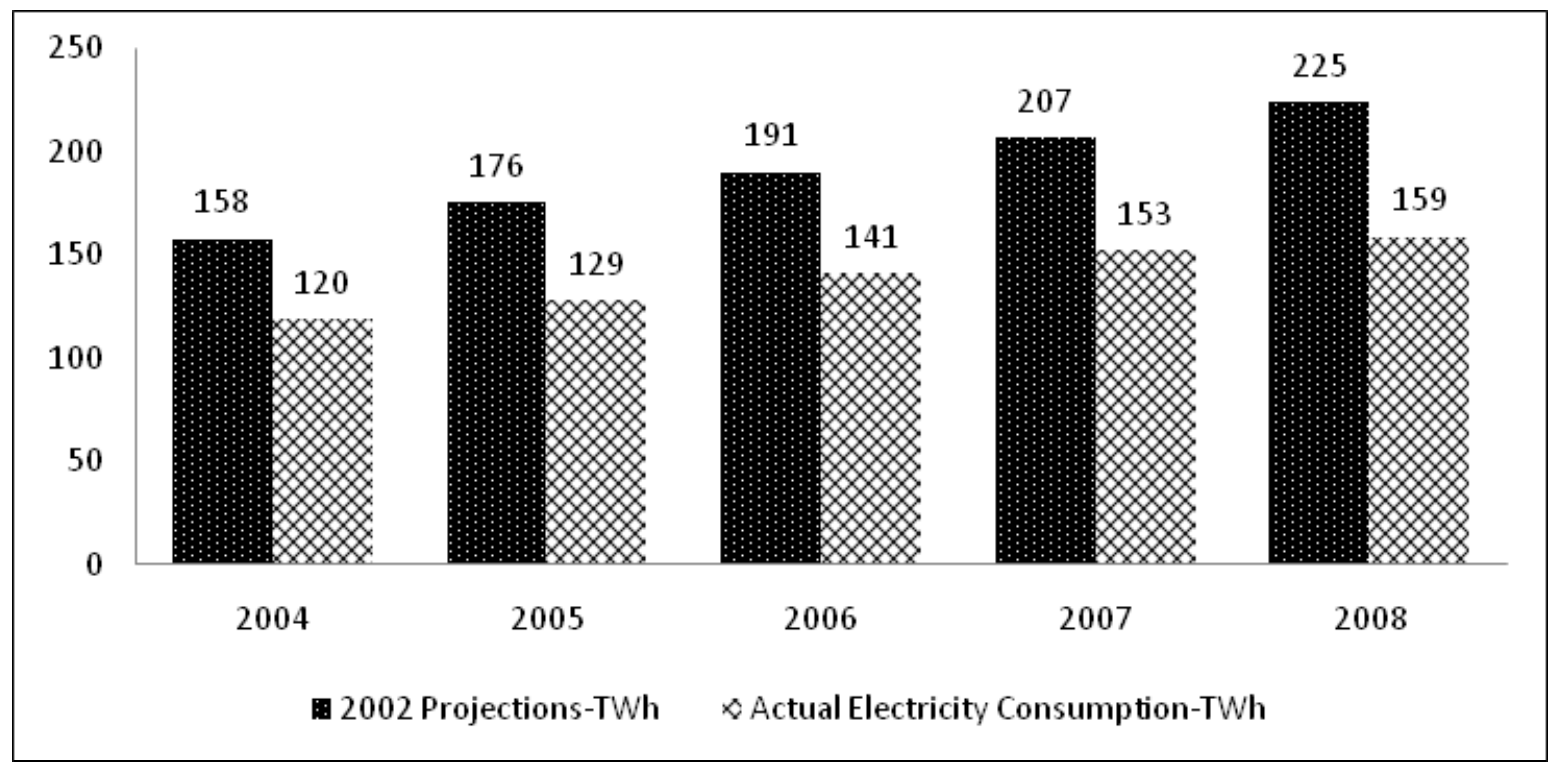

Source: [4] and [1]

There are only a limited number of previous academic studies focussing on Turkish aggregate electricity demand, although there has been an increase since the early 2000 s. These include Bakirtas et al. [6], Erdogdu [7], Ozturk and Ceylan [8], Kavaklioglu et al. [9], Hamzacebi [10] and Akay and Atak [11]; some of which attempt to identify a Turkish aggregate electricity demand relationship, some of which attempt to forecast future aggregate electricity demand, and some of which attempt to both; these are briefly reviewed below. 


\section{Figure 3: Fuel Source for Turkish Electricity Output ${ }^{2}$ TWh}

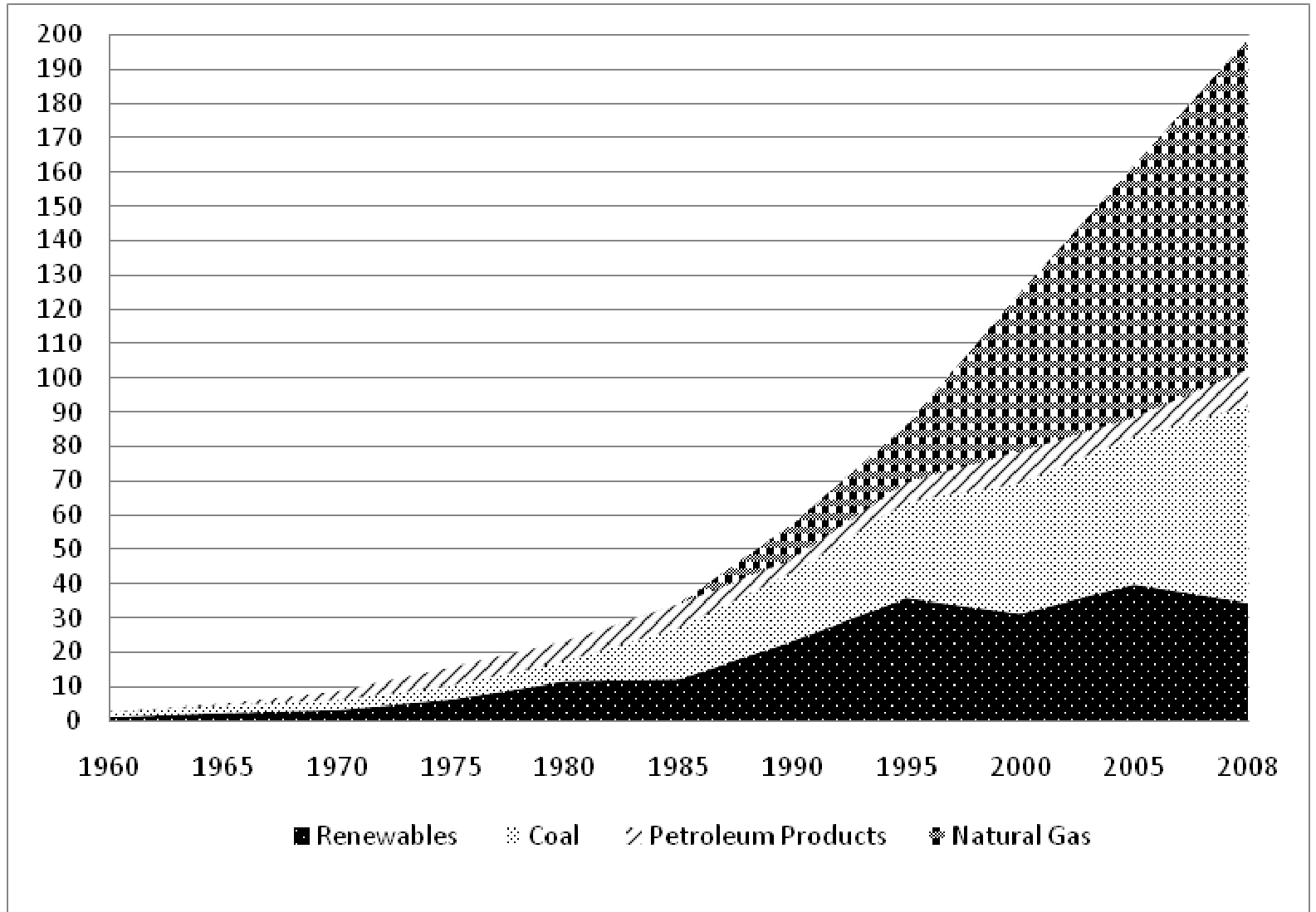

*Source: [1]

Bakirtas et al. [6] used the cointegration technique with annual data to explore the relationship between per capita aggregate electricity consumption, income per capita, and price for the period 1962 to 1996 . However, they did not find a significant price effect, stating this was to be expected given electricity prices were subsidised by various Turkish governments. This is a little surprising given that the degree of variability in Turkish real electricity prices appears to have been somewhat greater than general European real electricity prices, as illustrated in Figure 4. Nevertheless Bakirtas et al. [6] did find income per capita to be significant with estimated short and long run elasticities of about 0.7 and 3.1 respectively. Furthermore, as a separate exercise, Bakirtas et al. [6] utilised a simple univariate autoregressive moving

\footnotetext{
${ }^{2}$ Note, that the electricity output figures are different from total final electricity consumption which excludes exports, industry own use and distribution losses.
} 
average (ARMA) model to forecast future Turkish aggregate electricity demand per capita for the period 1997 to 2010 and concluded that it would be about $2222 \mathrm{kWh}$ in 2010 .

Figure 4: Comparison of OECD-Europe and Turkey Real Electricity Prices 1978-2008 A: Industrial Electricity Prices (2005 constant US \$ PPP / kWh)

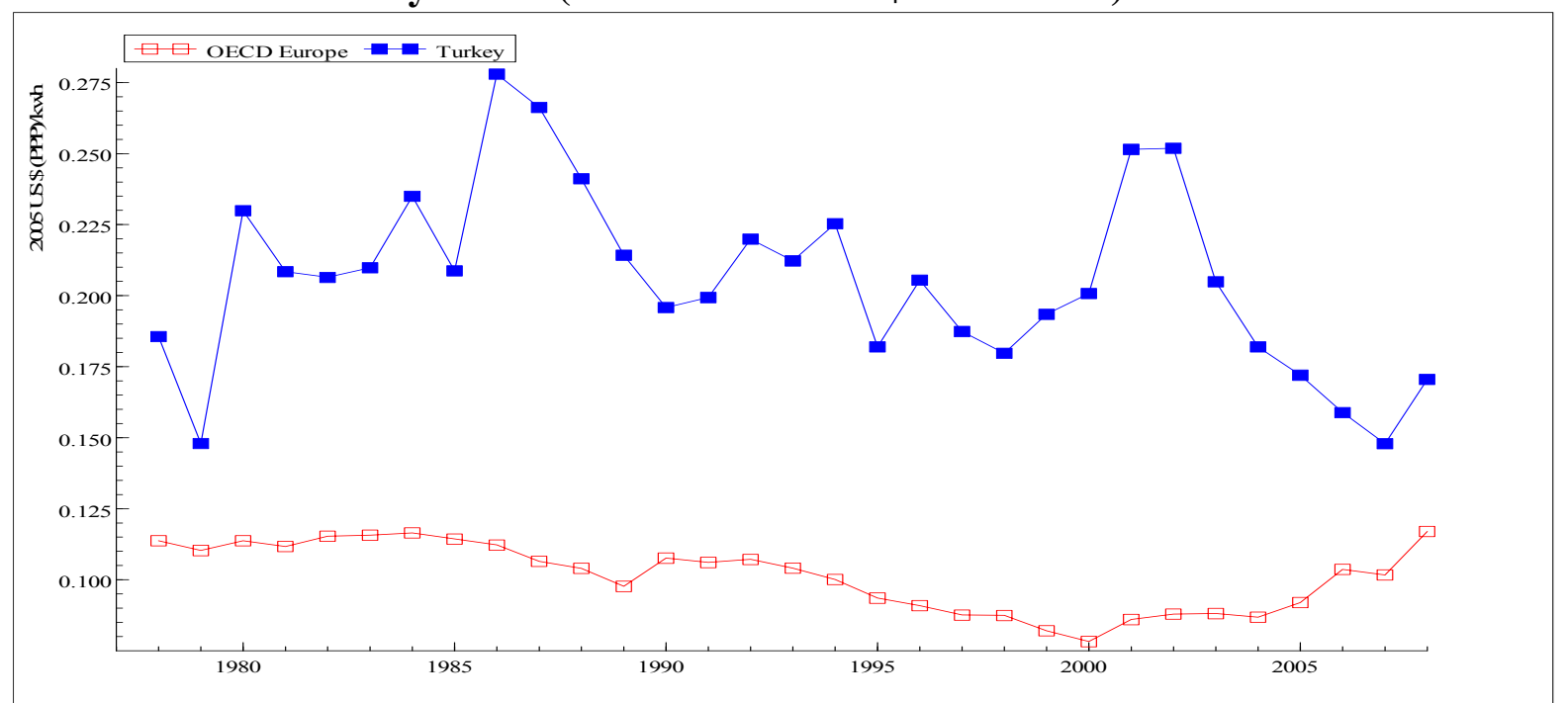

\section{B: Residential Electricity Prices (2005 constant US \$ PPP / kWh)}

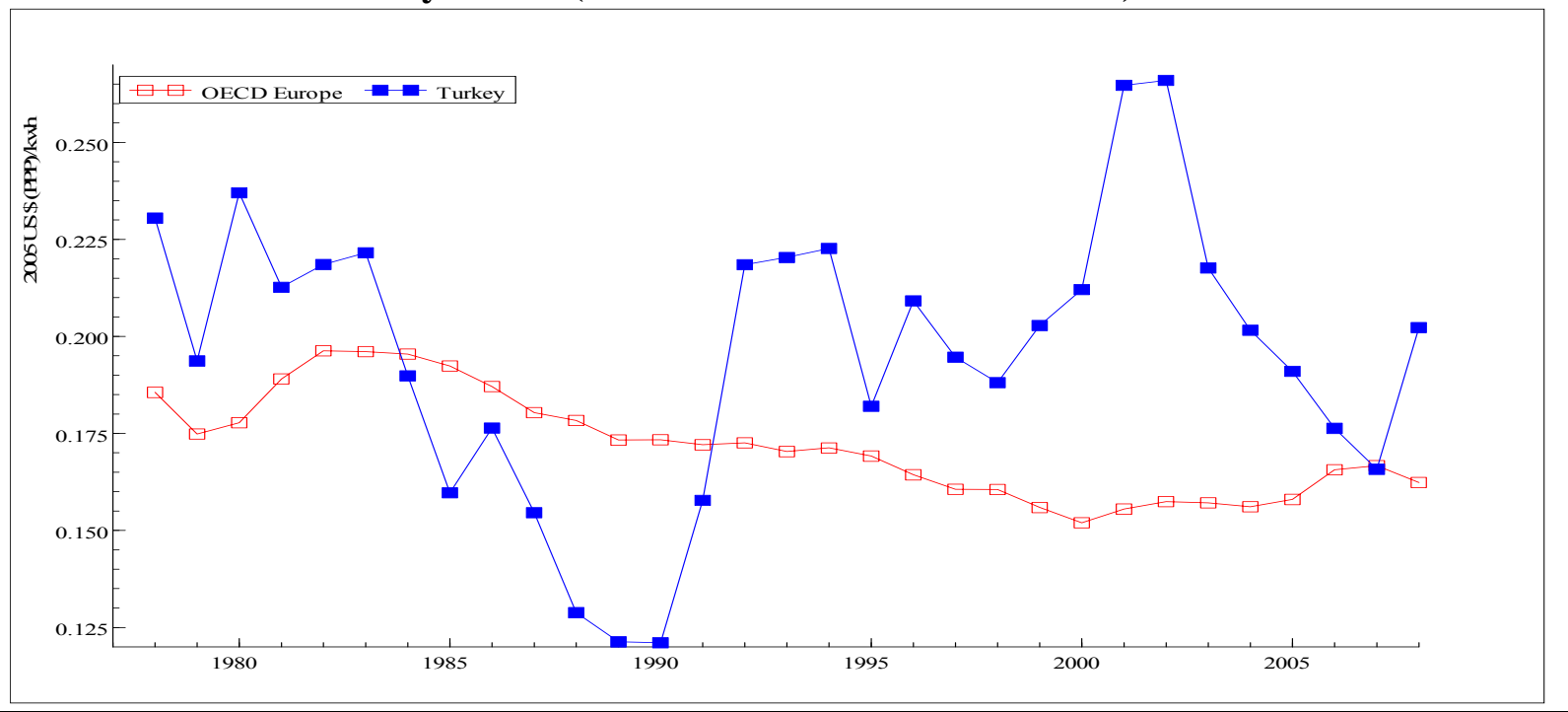

*Source: [1].

Erdogdu [7] used a Partial Adjustment Model (PAM) with quarterly data to explore the relationship between per capita electricity consumption ${ }^{3}$, per capita real GDP, and price for the period 1984 and 2004. He found short and long run price elasticities of -0.04 and -0.30

\footnotetext{
${ }^{3}$ Erdogdu [7] actually refers to this as 'net electricity consumption'.
} 
respectively and short and long run income elasticities of 0.06 and 0.41 respectively. However, Erdogdu [7] states that "data on net electricity consumption, population and GDP is not available quarterly" hence the annual series on these data were "converted into quarterly data by linear interpolation so as to make use of them together with quarterly data on electricity prices" [p. 1134]. This might have helped overcome the problem of insufficient data and observations, but possibly introduced an 'artificial data generating process' given three out of the four series used (including the dependent variable) had an artificial seasonal pattern imposed and might well have led to biased estimated elasticities. ${ }^{4}$ Similar to Bakirtas et al. [6], Erdogdu [7] undertakes a separate analysis to produce a forecast of future Turkish electricity demand. ${ }^{5}$ Erdogdu [7] utilised a simple univariate autoregressive integrated moving average (ARIMA) model estimated with annual data ${ }^{6}$ over the period 1923 to 2004 and concluded that Turkish aggregate electricity demand would increase by $3.3 \%$ percent per year until 2014 reaching about 156 TWh in 2010 and about 160 TWh in 2014.

Ozturk and Ceylan [8] used the Genetic Algorithm approach with annual data to investigate the relationship between aggregate electricity consumption, population, imports, exports and GDP for the period 1980 to 2003. Despite identifying a number of explanatory economic variables, their interaction with electricity consumption is not made clear; furthermore, electricity prices were omitted from the analysis. Nevertheless Ozturk and Ceylan [8] concluded that aggregate electricity demand would be between about 462 TWh and 500 TWh in 2020 .

\footnotetext{
${ }^{4}$ For example, GDP fluctuates seasonally and electricity-using appliances are likely to differ seasonally; hence, the simple linear interpolation is likely to ignore these seasonal fluctuations. Thus, it is likely that this would have led to the mis-identification of the electricity demand relationship.

${ }^{5}$ Although the first part of the paper is conducted in per capita terms, the forecast is for actual electricity demand.

${ }^{6}$ Unlike the first part of the paper that used 'quarterly data'.
} 
Kavaklioglu et al. [9] used the artificial neural network model with annual data for the period 1975 and 2006 to examine the relationship between aggregate electricity consumption, population, GDP, imports and exports and concluded that Turkish aggregate electricity demand would reach 240 TWh by 2020. However, like Ozturk and Ceylan [8], Kavaklioglu et al. [9] do not clearly identify the relationship between the explanatory economic variables and electricity consumption; moreover, once again the effect of electricity prices on electricity demand is ignored.

Hamzacebi [10] also used the artificial neural network model with annual data for the period 1970 and 2004 to analyse sectoral electricity consumption in order to forecast sectoral and aggregate electricity demand and concluded that aggregate electricity demand would be just below 500 TWh in 2020. Whereas Akay and Atak [11] employed the Grey Prediction with Rolling Mechanism method with annual data for the period 1970-2004 in order to forecast aggregate and industrial electricity consumption and suggested that aggregate electricity demand would be just below 266 TWh by 2015 .

The above summary highlights that Bakirtas et al. [6], Erdogdu [7], Hamzacebi [10] and Akay and Atak [11] all made use of techniques that effectively only used past electricity consumption to drive their forecasts of electricity demand. They therefore ignored any demand relationship and the important interaction between electricity consumption and economic variables such as income and price. Ozturk and Ceylan [8] and Kavaklioglu et al. [9] do however include some economic variables in their models but it is not clear how the economic variables contribute to driving the electricity demand projections. This suggests that there is room for improvement in this area with a need to determine firstly an acceptable Turkish aggregate electricity demand function and secondly to use this estimated relationship 
to produce future forecast scenarios. This is therefore undertaken here, with the methodology discussed in the next section.

\section{Methodology}

As stated above the STSM (Harvey [12]) coupled with the UEDT (Hunt et al. [13]) is used to estimate a Turkish aggregate electricity demand relationship. The STSM decomposes a time series into explanatory variables, a stochastic trend and an irregular component. The state space form presentation of a STSM presents the best estimates of the parameters and trend component at a given time. As additional observations are included, the parameters and the unobserved components of the model, such as the trend, are estimated by a combination of a recursive filtering and smoothing process by the Kalman Filter [14] and the maximum likelihood approach.

Electricity is not demanded for its own sake. It is a derived demand that comes from the demand for lighting, heating, cooling, etc. and consequently there are a number of exogenous factors that might influence electricity demand behaviour. These include improved technical efficiency of the capital and appliance stock, and changes in consumer tastes, preferences, demographics, social structures, environmental regulations, economic structure, etc. However, these factors are generally difficult to observe directly but arguably play an important role in determining electricity demand behaviour; hence, an estimated stochastic UEDT via the STSM is an ideal proxy (as advocated by Hunt et al. [13]) since the trend component attempts to capture the unobserved components. Given these advantages a number of energy demand studies have utilised the STSM approach; for example Doornat et al. [15] and Harvey and Koopman [16], Hunt et al. [13], Hunt and Ninomiya [17], Hunt et al. 
[18], Hunt et al. [19], Dimitropoulos et al. [20], Amarawickma and Hunt [21], Dilaver and Hunt [22], and Dilaver and Hunt [23]. As stated above, this approach is also taken here and is explained further below.

Using a similar framework to Dilaver and Hunt [22] and Dilaver and Hunt [23], Turkey's aggregate electricity demand is assumed to be represented by:

$$
E_{t}=f\left(Y_{t}, P_{t}, U E D T_{t}\right)
$$

where;

$$
\begin{aligned}
& E_{t}=\text { Aggregate Electricity Demand } . \\
& Y_{t}=\text { Gross Domestic Product. } \\
& P_{t}=\text { Real Average Electricity Price. } \\
& U E D T_{t}=\text { Underlying Energy Demand Trend for Aggregate Turkish Electricity }
\end{aligned}
$$

For the econometric estimation of equation (1), a general dynamic autoregressive distributed lag specification is estimated as follows:

$$
A(L) e_{t}=B(L) y_{t}+C(L) p_{t}+U E D T_{t}+\epsilon_{t}
$$

where; $A(L)$ is the polynomial lag operator $1-\lambda_{1} L-\lambda_{2} L^{2}-\lambda_{3} L^{3}-\lambda_{4} L^{4}, B(L)$ is the polynomial lag operator $1+\alpha_{1} L+\alpha_{2} L^{2}+\alpha_{3} L^{3}+\alpha_{4} L^{4}$ and $C(L)$ is the polynomial lag operator $1+\varphi_{1} L+\varphi_{2} L^{2}$ $+\varphi_{3} L^{3}+\varphi_{4} L^{4}$ and ${ }^{7}$

$$
\begin{aligned}
& e_{t}=\operatorname{Ln}\left(E_{t}\right) \\
& y_{t}=\operatorname{Ln}\left(Y_{t}\right) \\
& p_{t}=\operatorname{Ln}\left(P_{t}\right) \\
& B(L) / A(L)=\text { the long run income elasticity of aggregate electricity demand; } \\
& C(L) / A(L)=\text { the long run price elasticity of aggregate electricity demand; and }
\end{aligned}
$$

\footnotetext{
${ }^{7}$ A four-year lag is assumed since it is believed this is long enough to capture any possible dynamics.
} 
$U E D T_{t}=$ the value of UEDT at period $t$

$\varepsilon_{t}=$ a random error term.

The UEDT is a stochastic process and identified by:

$$
\begin{array}{ll}
\mu_{t}=\mu_{t-1}+\beta_{t}+\eta_{t} ; & \eta_{t} \sim N I D\left(0, \sigma_{\eta}^{2}\right) \\
\beta_{t}=\beta_{t-1}+\xi_{t} ; & \xi_{t} \sim N I D\left(0, \sigma_{\xi}^{2}\right)
\end{array}
$$

Where $\mu_{\mathrm{t}}$ and $\beta_{\mathrm{t}}$ represent UEDT level and slope respectively and $\eta_{t}$ and $\xi_{t}$ are the mutually uncorrelated white noise disturbances for the level and slope with zero means and variances $\sigma_{\eta}^{2}$ and $\sigma_{\xi}^{2}$ respectively. These are also known as hyper-parameters and determine the shape of the aggregate electricity UEDT.

Equation (3) and Equation (4) show that the level and slope disturbances $\left(\eta_{t}\right.$ and $\left.\xi_{t}\right)$ are assumed to be normally distributed. Therefore, when using the STSM in this way it is sometimes necessary to include some level and/or slope interventions to ensure the normality of the auxiliary residuals (irregular, level and slope) is maintained (Harvey and Koopman [24]). Moreover, as Harvey and Koopman [24] highlight these interventions often provide information about important breaks and structural changes at certain dates within the estimation period, so that in the presence of such interventions the $U E D T_{t}$ is given by:

$$
U E D T_{t}=\mu_{t}+\text { irregular interventions }+ \text { level interventions }+ \text { slope interventions }
$$

Therefore, Equation (2), Equation (3) and Equation (4) are initially estimated by a combination of maximum likelihood and the Kalman filter. Insignificant variables are then gradually eliminated and interventions added but ensuring the model passes an array of diagnostic tests (detailed below) until the preferred parsimonious model is obtained. The 
software package STAMP 8.10 [25] is used for the estimation, which is presented in the next section.

\section{Data and Estimation Results}

\subsection{Data}

Annual time series data from 1960 to 2008 for E (Turkish aggregate electricity consumption in $\mathrm{kWh}$ ), Y (Turkish GDP in 2005 constant Yeni Turk Lirasi, YTL), and P (real average Turkish electricity prices in 2005 constant YTL) are used for the analysis. E is obtained from the International Energy Agency (IEA [1]), nominal GDP from the World Bank [26] and nominal residential and industrial electricity prices from the archives of the SIS, the MENR and the IEA [1]. The weighted averages of nominal industrial and residential prices are used in order to calculate an approximation for the nominal average aggregate electricity price, which is deflated by the Consumer Price Index (CPI, 2005=100) obtained from the World Bank [26] in order to obtain P. Similarly, nominal GDP figures are deflated by the CPI to obtain Y.

\subsection{Estimation Results}

After following the estimation strategy outlined above the preferred estimated equation is given by:

$e_{t}=0.16947 y_{t}-0.11101 p_{t}+U E D T_{2008}$

where the estimated UEDT 2008 is 20.95 at the end of the period, with a slope of 0.0608 . The detailed estimation results and the diagnostics tests are given in Table 1 and Figure 5. 
The preferred model presented in Table 1 passes all the diagnostic tests including the nonnormality test for both the residuals and the auxiliary residuals, and the prediction tests for 2001 thru 2008 (as illustrated in Figure 5). To achieve this, two level interventions (1976 and 1979) are included in the preferred model probably reflecting a combination of different events. These include the unusually high changes in Turkish GDP, real electricity prices, and electricity consumption in $1976^{8}$, the compulsory electricity cuts that were introduced in the early 1970s and peaked in 1980 (as illustrated in Figure 6) [27], and the oil price hike in 1979 that according to Taymaz and Yilmaz [28] led to the worst political instability in Turkish history. ${ }^{9}$ The effects of which are unlikely to be captured adequately by the estimated income and price elasticities (being outside the usual 'norm').

Despite the interventions, the resultant estimated UEDT (illustrated in Figure 7A) generally increases but at a decreasing rate (illustrated in Figure 7B). This suggests that any energy efficiency improvements due to technical progress of the capital and appliance stock is outweighed by other exogenous factors; hence the estimated UEDT represents 'electricity using' behaviour.

\footnotetext{
${ }^{8}$ GDP increased by $9 \%$, prices fell by $12 \%$, and electricity consumption increased by $20 \%$ in 1976 .

${ }^{9}$ Turkish inflation was above $64 \%$ and there was a balance of payments 'crisis' in 1979 , with a subsequent large decrease in GDP in 1980 that led to a military coup [28].
} 
Table 1: Turkish Aggregate Electricity Demand STSM Estimates and Diagnostics

Sample 1960-2008

\begin{tabular}{|lccc}
\hline Variables & $\begin{array}{c}\text { Estimated } \\
\text { Coefficients }\end{array}$ & T Values & Prob. \\
$\mathrm{y}_{\mathrm{t}}$ & 0.1695 & 3.762 & 0.001 \\
$\mathrm{p}_{\mathrm{t}}$ & -0.1110 & -3.563 & 0.001 \\
1976 Level & 0.0923 & -3.003 & 0.004 \\
1979 Level & -0.0850 & 2.750 & 0.009
\end{tabular}

Level and Slope Components' of UEDT 2008

Level : $\quad 20.9526$

Slope : $\quad 0.0608$

Diagnostics

Residuals

Auxiliary Residuals

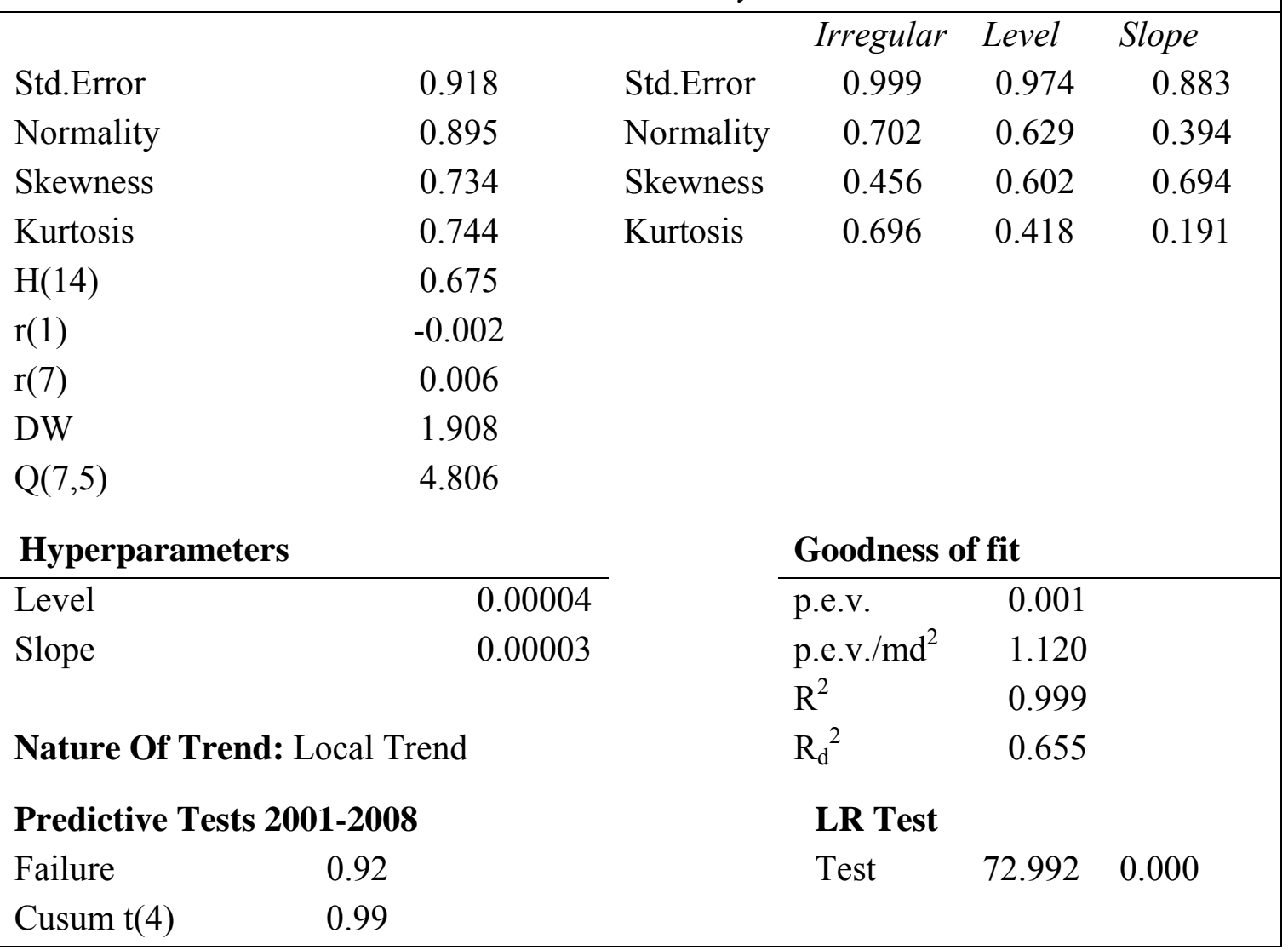

Notes:

- Model estimation and all statistics are from STAMP 8.10;

- $\quad$ Model includes level interventions for 1976 and 1979;

- Prediction Error Variance (p.e.v.), Prediction Error Mean Deviation (p.e.v./m.d.2) and the Coefficients of Determination $\left(R^{2}\right.$ and $\left.R d^{2}\right)$ are all measures of goodness-of-fit;

- Normality (corrected Bowman - Shenton), Kurtosis and Skewness are error normality statistics, all approximately distributed as $\chi^{2}$ (2); as $\chi^{2}$ (1); as $\chi^{2}$ (1) respectively;

- $\quad H(14)$ is a Heteroscedasticity statistic distributed as F(14,14);

- $\quad r(1)$ and $r(7)$ are the serial correlation coefficients at the equivalent residual lags, approximately normally distributed;

- $\quad D W$ is the Durbin-Watson statistic;

- $\quad Q(7,6)$ is the Box - Ljung statistic distributed as $\chi^{2}(6)$;

- Failure is a predictive failure statistic distributed as $\chi^{2}$ (8);Cusum is a mean stability statistic distributed as the Student $t$ distribution; both are STAMP prediction tests found by re-estimating the preferred model up to 2000 and predicting for 2001 thru 2008.

- The LR Test represents a likelihood ratio test on the same specification after imposing a fixed level and slope hyperparameter, distributed as $\chi^{2(2)}$ and probabilities are given in parenthesis. 
Figure 5: STAMP Predictive Tests Graphics 2001-2008

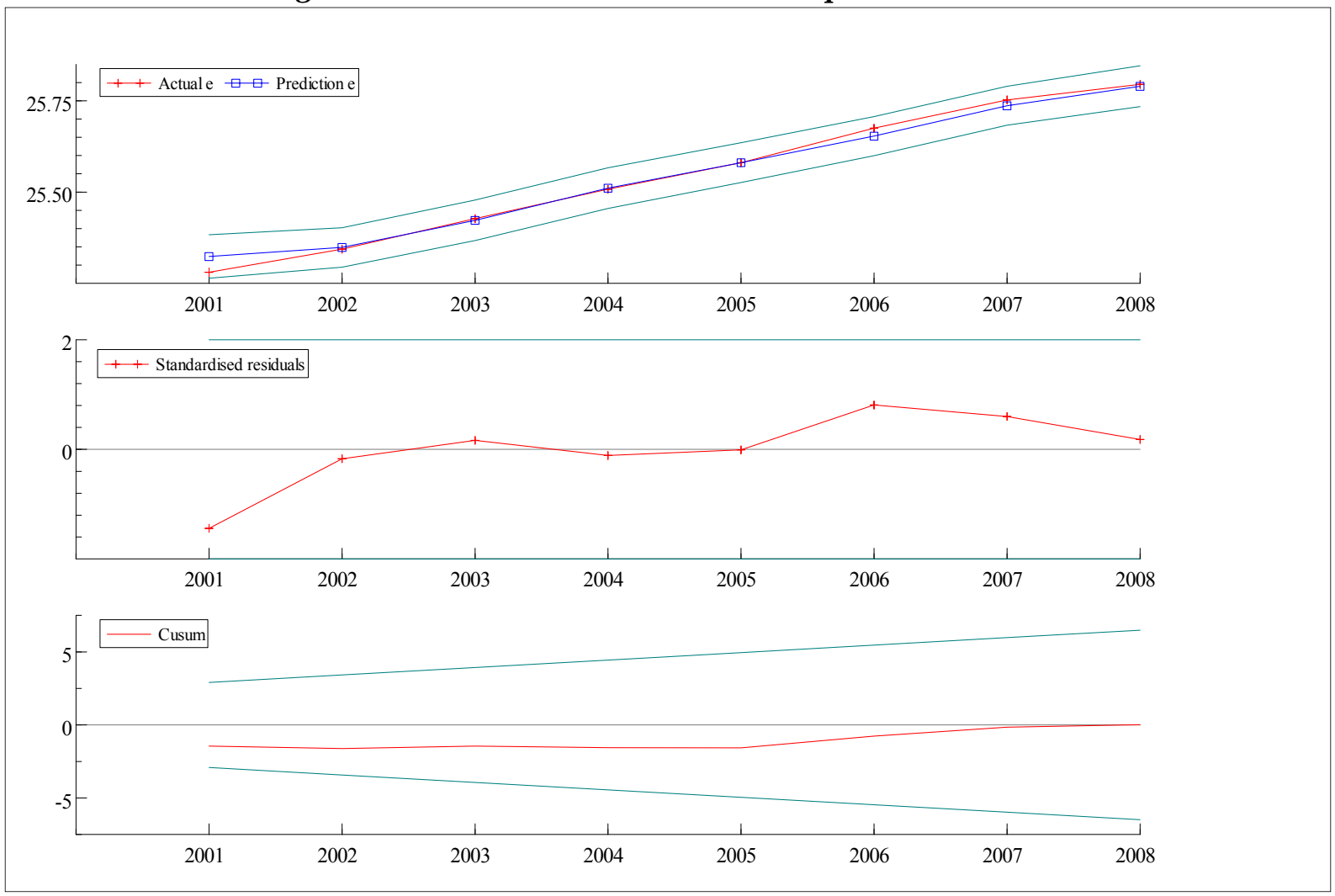

Figure 6: Compulsory Electricity Cuts 1971-1983

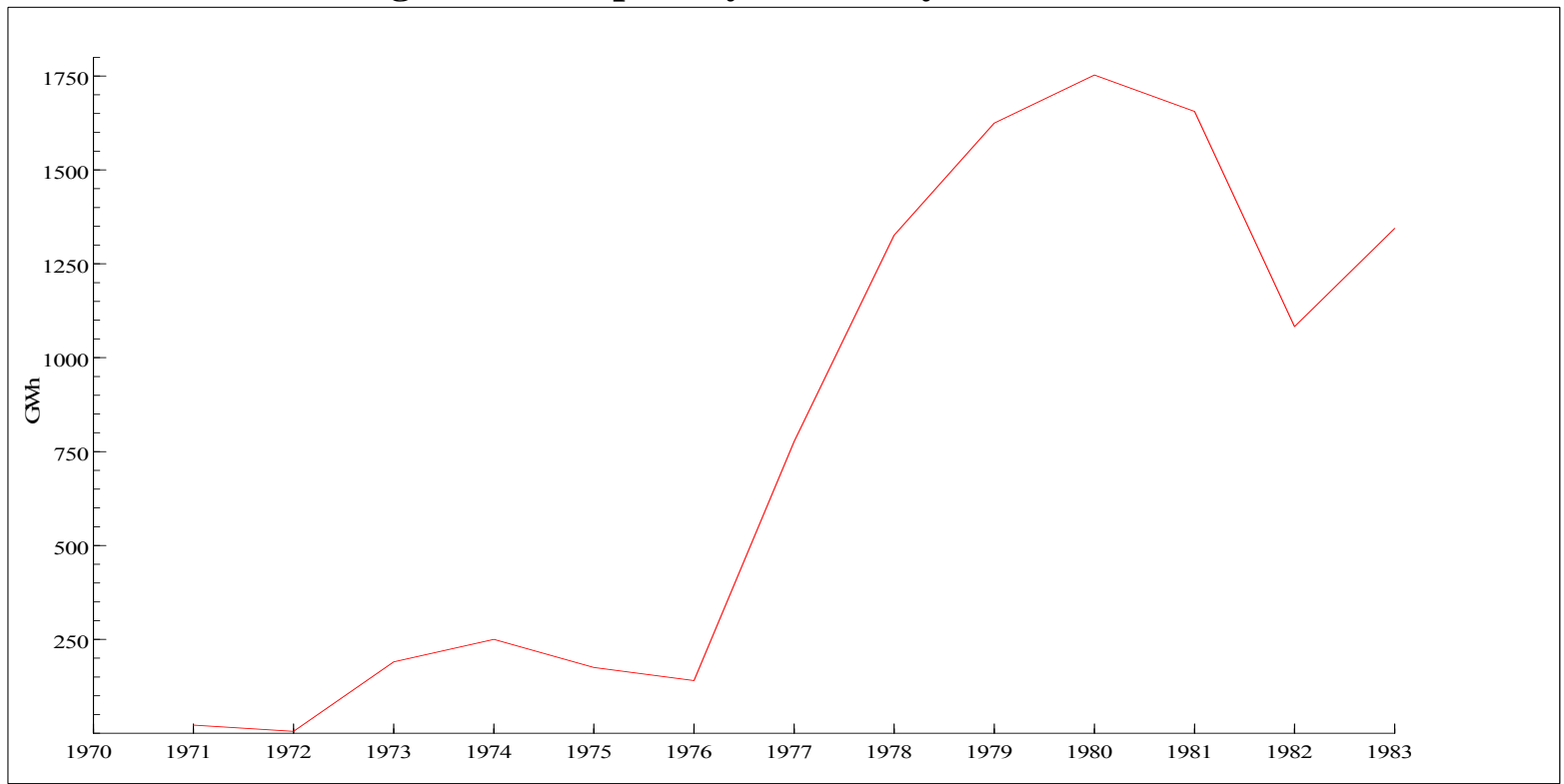

*Source: [27]

The preferred model in Table 1 does not include any dynamic terms, suggesting the short run and long run income and price elasticities are 0.17 and -0.11 respectively. The estimated income elasticity being somewhat lower than those obtained by Bakirtas [6] and Erdogdu [7] 
and the estimated price elasticity being smaller (in absolute terms) than that obtained by Erdogdu [7] (see Table 2 for a comparison). One reason for the difference might be that these previous studies did not allow for the impact of a stochastic UEDT in their analysis. With the estimation complete, the next section details the construction of the future forecast scenarios for Turkish aggregate electricity demand based upon the preferred equation.

Figure 7: Estimated UEDT for Turkish Electricity Demand 1960-2008

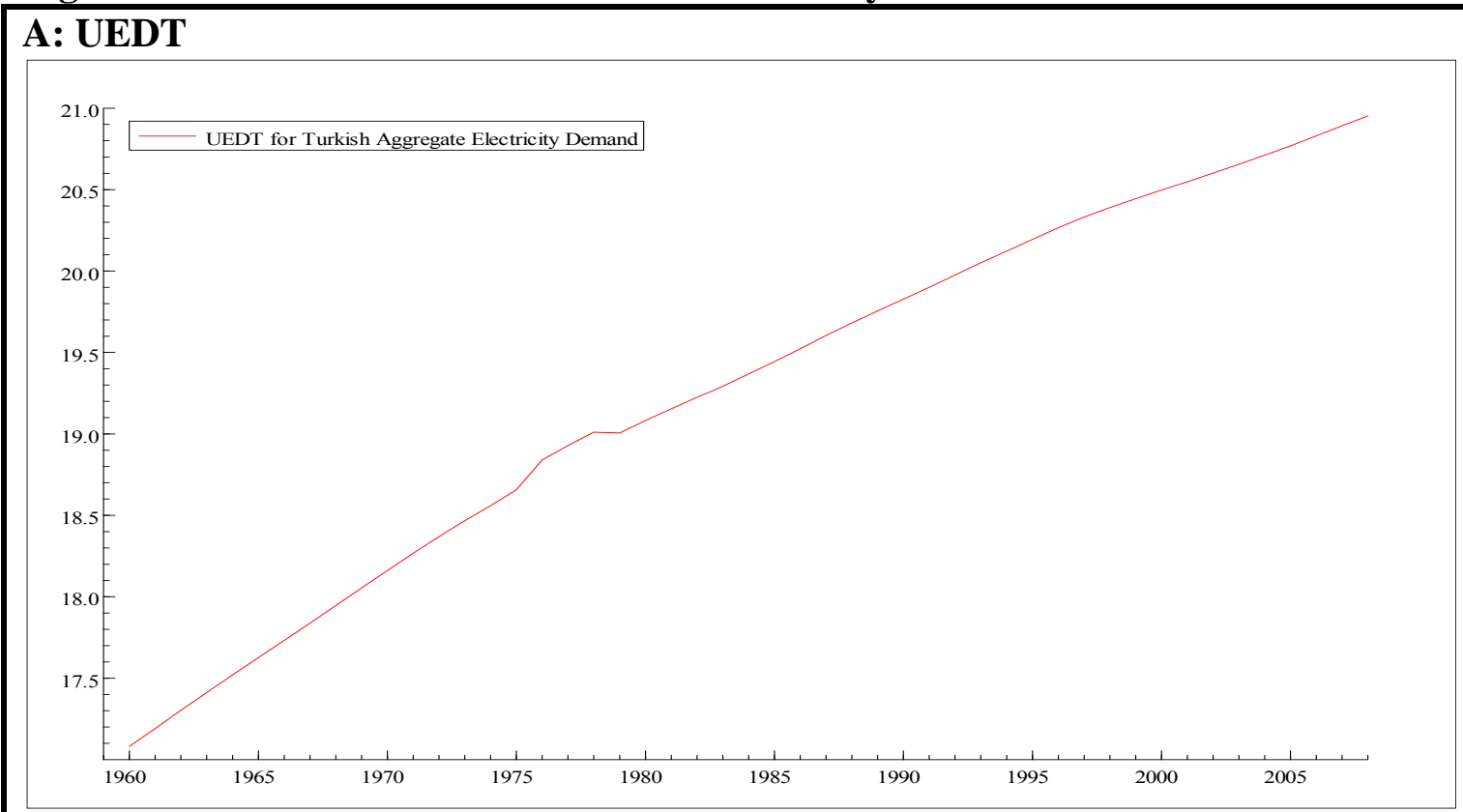

\section{B: Slope of UEDT}

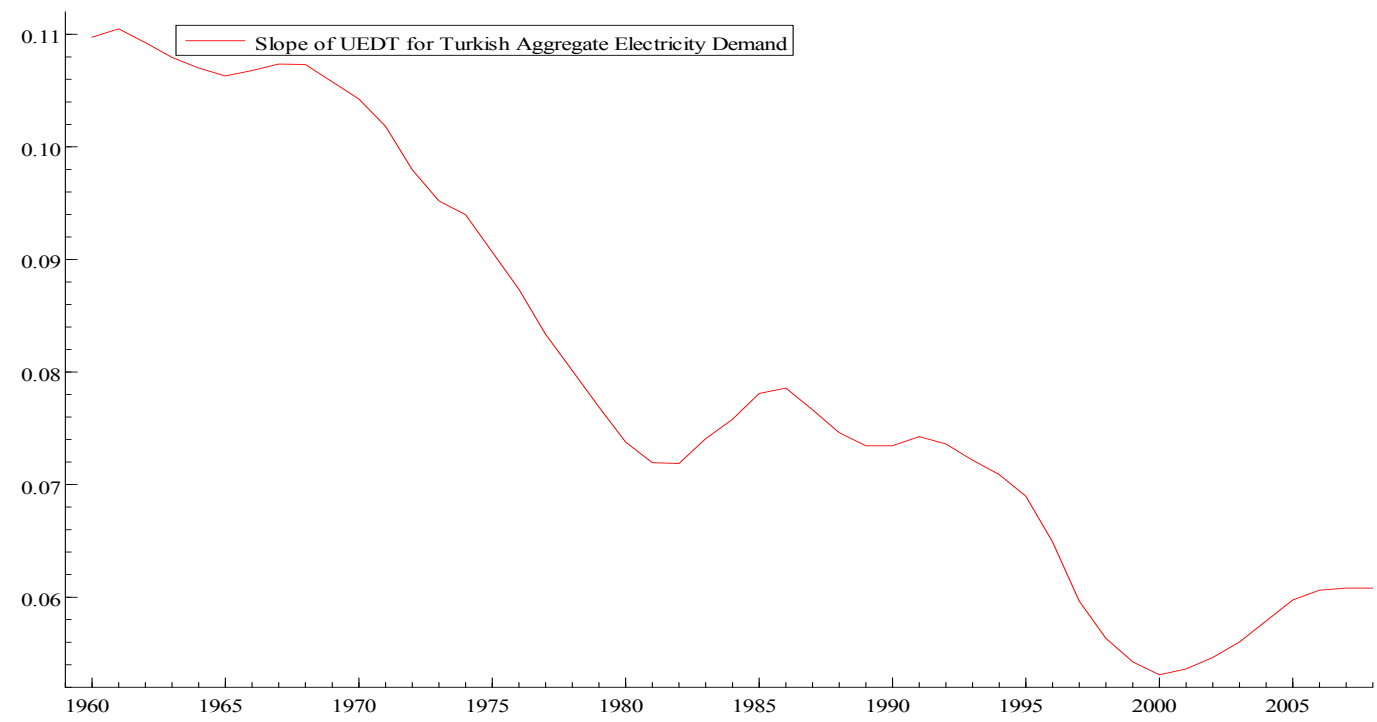


Table 2: Comparison of Estimated Long Run Elasticities

\begin{tabular}{|l|c|c|}
\hline Study & Price & Income \\
\hline Bakirtas et al. [6] & 0 & 3.13 \\
Erdogdu [7] & -0.29 & 0.41 \\
This Paper & -0.11 & 0.17 \\
\hline
\end{tabular}

\section{Forecast Scenarios}

In order to utilise the preferred equation discussed in the previous section to produce future forecast scenarios a number of assumptions are required for income, prices, etc. This section discusses these assumptions and presents the resultant scenarios.

\subsection{Assumptions}

Three forecast scenarios are produced: a 'low' case, a 'reference' case and a 'high' case. For the 'low' and 'high' cases a combination of assumptions for the economic variables and UEDT are chosen that produce sensible lower and upper bound forecasts for future Turkish electricity demand respectively. For the 'reference' case the 'most probable' outcome for the economic variables and UEDT are assumed (similar to 'business as usual' scenarios). ${ }^{10} \mathrm{~A}$ detailed discussion of these assumptions follows.

\footnotetext{
${ }^{10}$ However, given some information is available for average electricity prices for the year 2009, this information is used in all three scenarios. In 2009 the average price of electricity (weighted average of residential and industrial prices) prices increased by $18.5 \%$ in nominal terms. At the time of the writing, the required deflator (the Consumer Price Index from World Bank) is not available, although it is known that Turkish inflation was around $6.5 \%$ in 2009 ; hence based on this, average electricity price is assumed to have increased by $12 \%$ in 2009 for all three scenarios.
} 
Figure 8: Forecast Scenario assumptions for GDP and Average Real Electricity Prices, 2000-2020

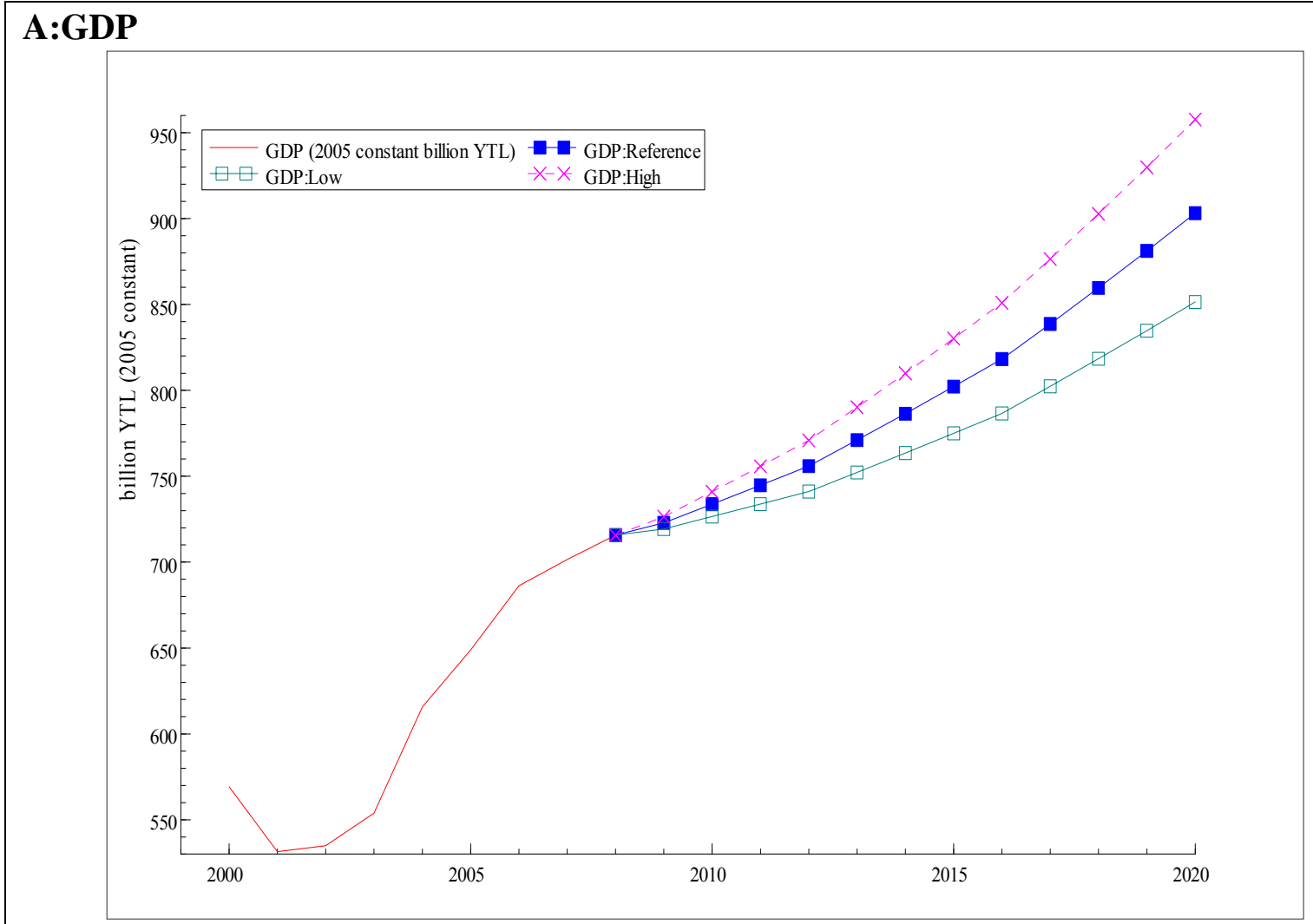

\section{B: Price}

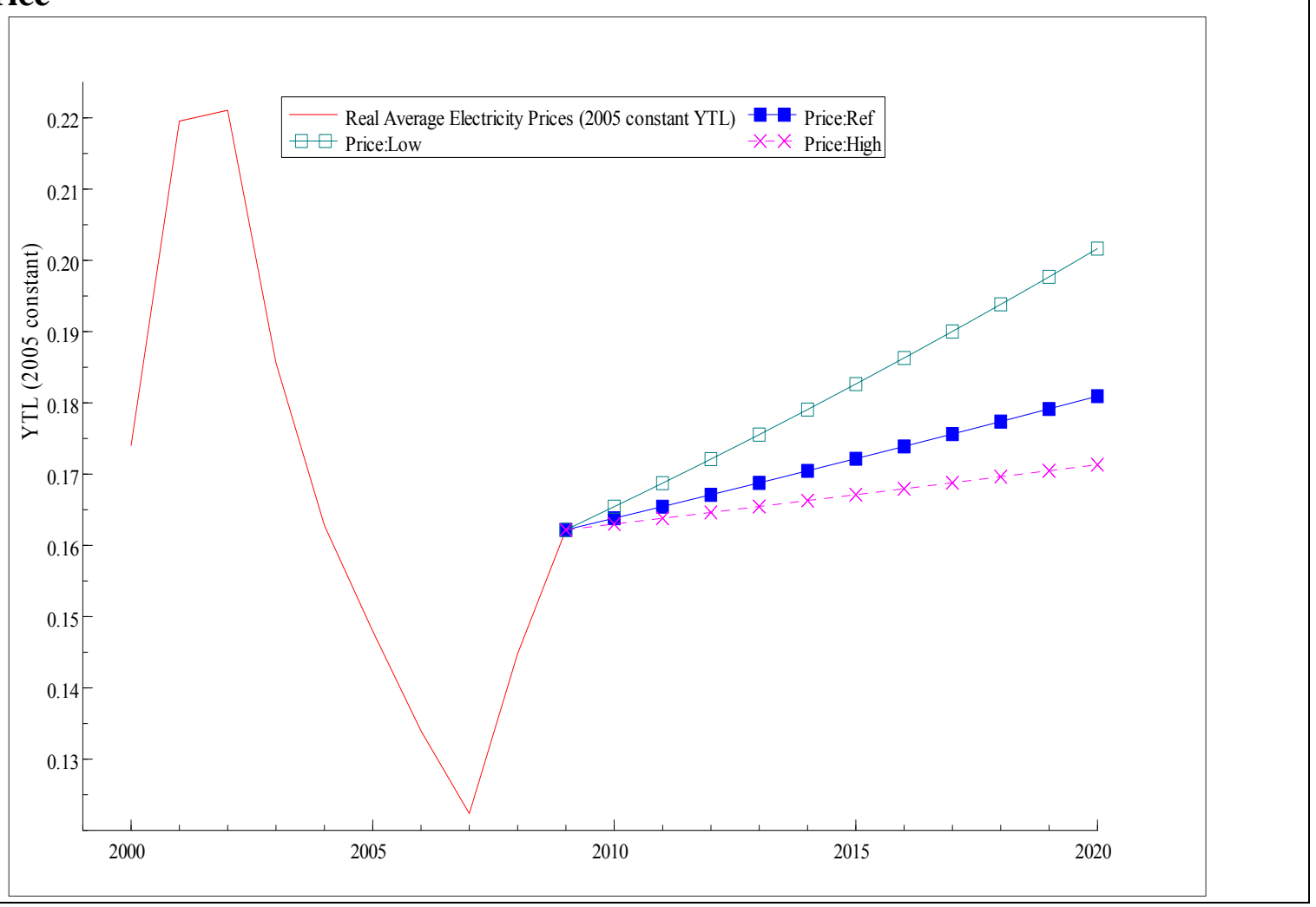


Figure 9: Forecast Scenario assumptions for the UEDT 2000-2020

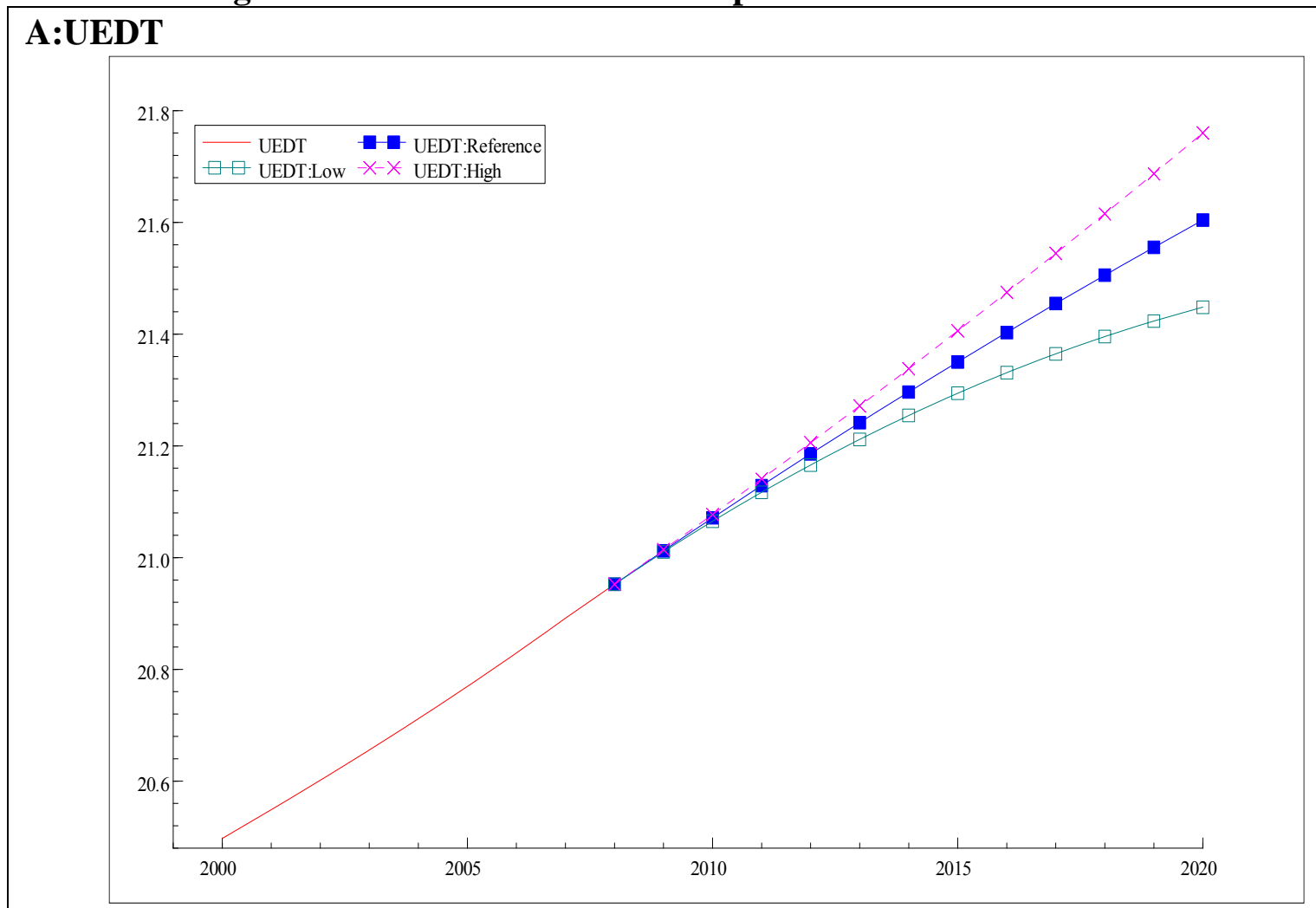

\section{B:Slope}

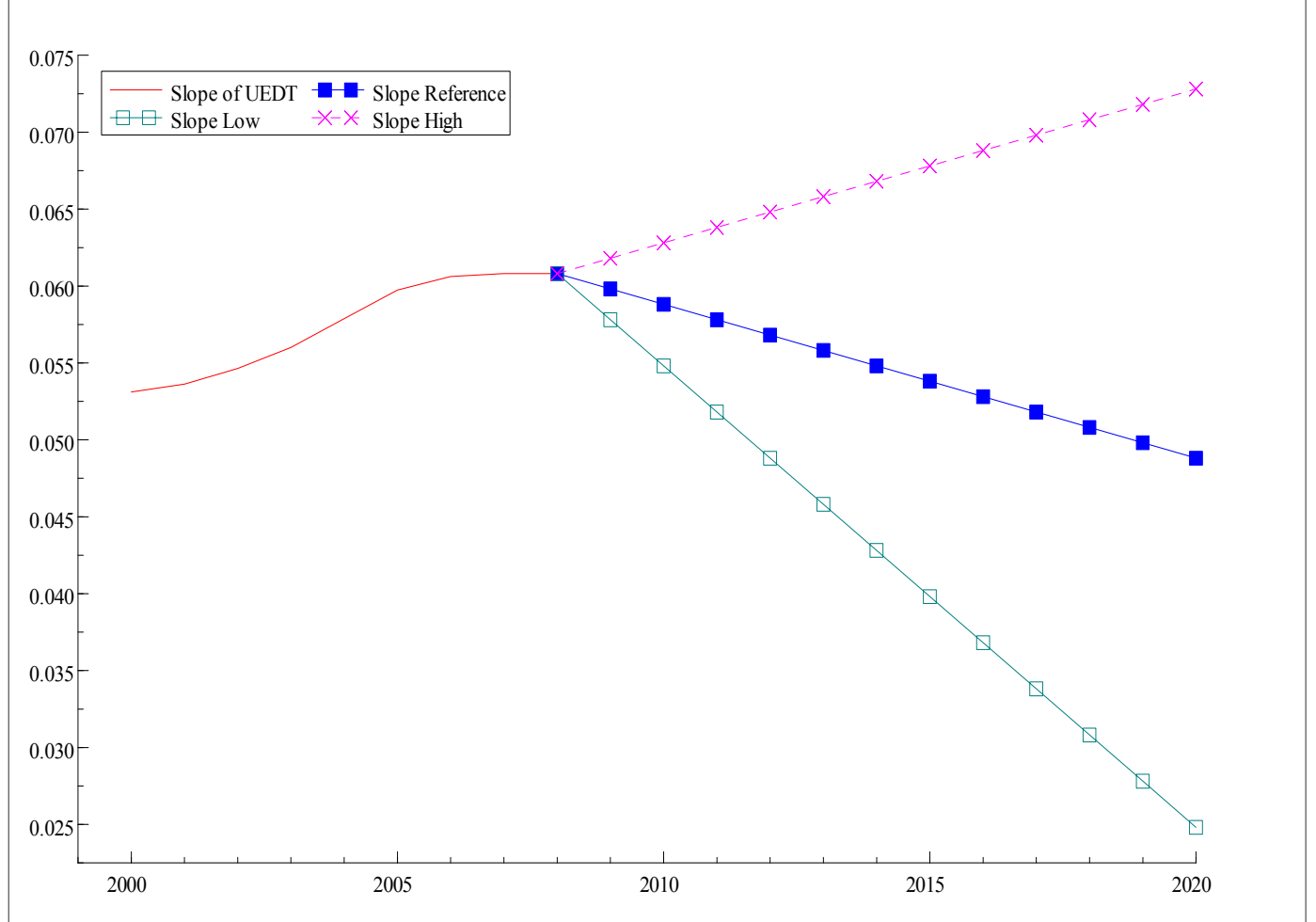

'Reference' case scenario: Average real electricity prices are assumed to increase by $1 \%$ per annum after 2009. This is based on the assumption that the Turkish government introduces 
measures to meet their requirements for the Kyoto Protocol (such as carbon taxes and incentives to encourage more renewables in power generation) although this is offset to some extent by a reduction in the cost of generation due to technological improvements. It is further assumed that GDP increases by only 1\% in 2009 due to the global economic slowdown, followed by a recovery period with GDP increasing by $1.5 \%$ per annum in 2010 thru 2012, 2\% per annum in 2013 thru 2016 and 2.5\% per annum thereafter. Additionally, the generally diminishing slope of the estimated UEDT of 0.001 per annum ${ }^{11}$ over the estimation period is projected to continue throughout the forecast period.

'Low' case scenario: Average real electricity prices are assumed to increase $2 \%$ per annum after 2009 since the efficiency improvements in power generation do not offset the increases as assumed in the 'reference' scenario. The impact of the global economic crises is assumed to be greater than the 'reference scenario' with GDP increasing by only $0.5 \%$ in 2009 and by only 1\% per annum in 2010 thru 2012 followed by a constrained recovery with GDP increasing by $1.5 \%$ per annum in 2013 thru 2016 and $2 \%$ per annum thereafter. Furthermore, the slope of the UEDT is projected to decrease by 0.003 per annum, suggesting that the 'electricity using' trend for electricity will continue, but at a slower pace.

'High' case scenario: Average real electricity prices are assumed to increase by only $0.5 \%$ per annum over the period 2010 to 2020 assuming that measures to help Turkey comply with the Kyoto Protocol requirements are offset more by the increasing efficiency in electricity generation than assumed in the 'reference' scenario. GDP is assumed to increase by $1.5 \%$ in 2009 despite the global slowdown, followed by a good recovery with GDP increasing $2 \%$ per annum in 2010 thru 2012, 2.5\% per annum in 2013 thru 2016, and 3\% per annum thereafter.

\footnotetext{
${ }^{11}$ The figure -0.001 being the average change in the estimated slope over the estimation period.
} 
Additionally, the slope of the UEDT is projected to increase 0.001 per annum from 2009 to 2020, suggesting that the 'electricity using' trend for electricity will continue, but at a faster pace.

These assumptions for GDP and prices are illustrated in Figure 8 and the assumptions for the UEDT illustrated in Figure 9. The resultant scenario outcomes are discussed below.

\subsection{Scenario Results}

Given the above assumptions, Turkish aggregate electricity demand is predicted to be 259 , 310 and 368 TWh in the 'low', 'reference' and 'high' case scenarios respectively with the paths to 2020 illustrated in Figure 10. Comparing to the previous projections in Table $3^{12}$ it can be seen that these forecasts are lower than, Ozturk and Ceylan [8], Hamzacebi [10] and Akay and Atak [11], but higher than Erdogdu [7] and Kavaklioglu et al. [9]. ${ }^{13}$

Table 3: Comparison with Previous Aggregate Electricity Demand Projections

\begin{tabular}{|c|c|c|c|c|c|c|c|c|c|}
\hline & & & & & & & & & \\
\hline Year & 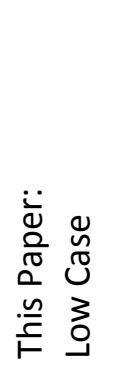 & 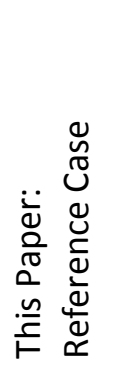 & 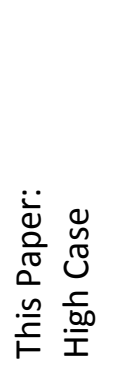 & 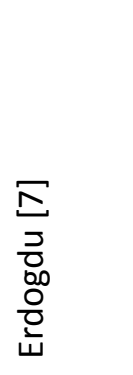 & 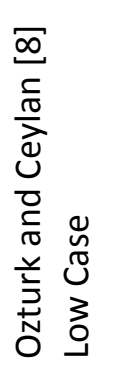 & 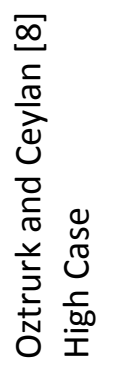 & 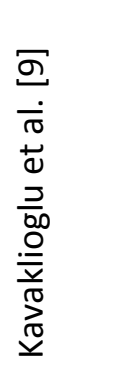 & 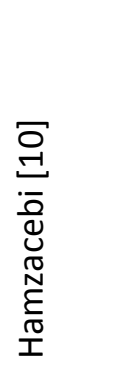 & 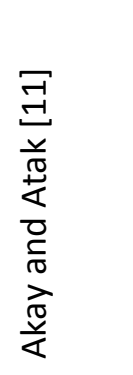 \\
\hline 2014 & 213 & 224 & 235 & 160 & - & - & 207 & 294 & - \\
\hline 2015 & 221 & 237 & 253 & - & - & - & 212 & 321 & 266 \\
\hline 2020 & 259 & 310 & 368 & - & 462 & 500 & 240 & 500 & - \\
\hline
\end{tabular}

\footnotetext{
${ }^{12}$ Note Bakirtas et al. [6] is not included in the table since their latest forecast was for 2010 and in per capita terms.

${ }^{13}$ However, given Turkish aggregate electricity consumption had reached just under 160TWh in 2008 (IEA [1]), Erdogdu's [7] forecast for 2014 looks to be somewhat improbable.
} 
Figure 10: Aggregate Turkish Electricity Demand Forecast Scenarios, 2009-2020

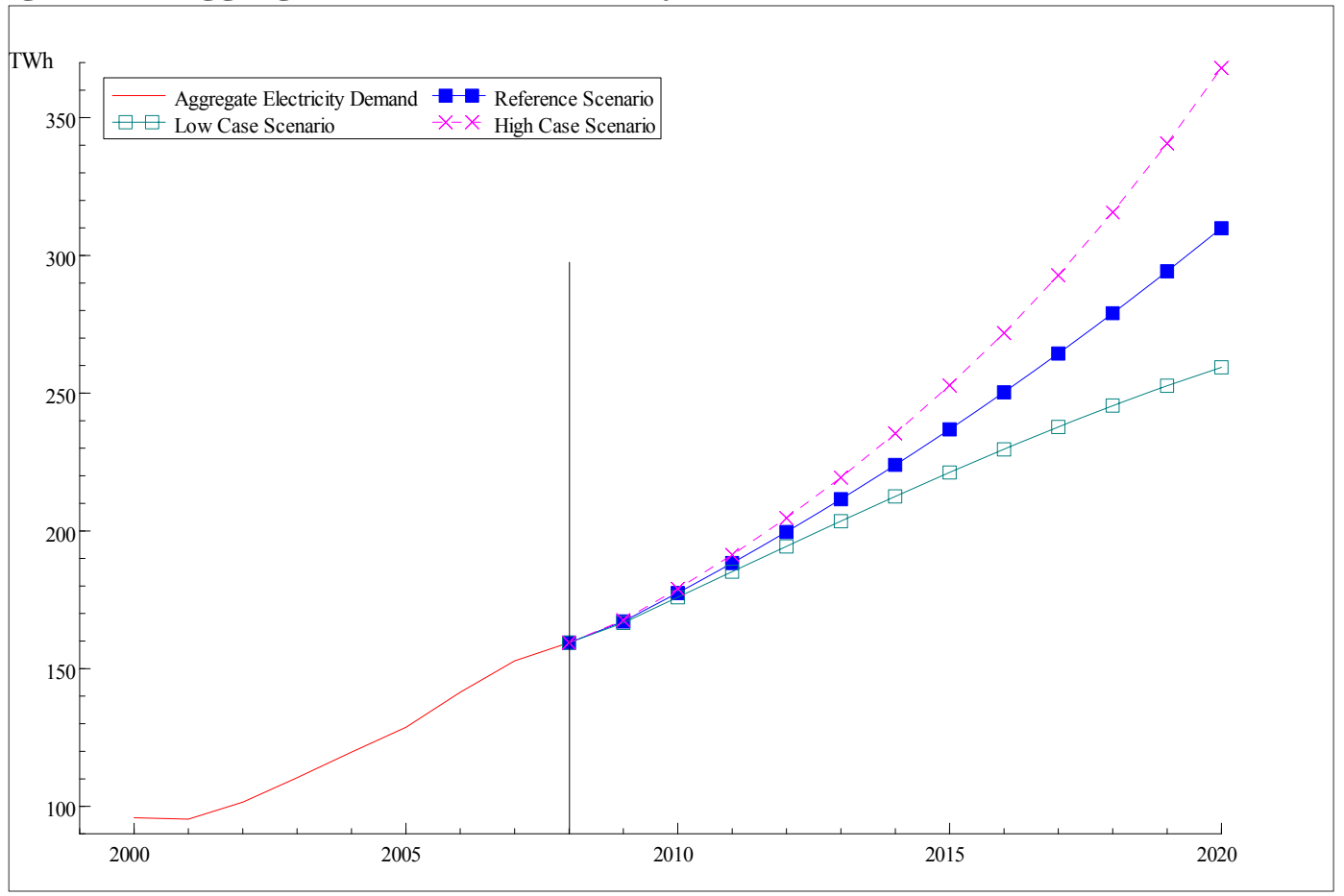

\section{Summary and Conclusion}

According to Ediger and Tatlidil [4], Keleş [5], and Ediger and Akar [29] previous forecasts of Turkish electricity demand were, on the hole, unsuccessful. Arguably, a key reason for this is the failure of previous studies to adequate capture the impact of the main economic drivers and the UEDT on Turkish electricity demand. This study attempts to rectify these perceived defects by using the STSM to estimate a Turkish aggregate electricity demand function and using it to produce future forecast scenarios. The estimated income and price elasticities are 0.17 and -0.11 respectively with an estimated stochastic trend that is generally upward sloping (but at a decreasing rate) - reflecting 'electricity using' behaviour over the estimation period. Furthermore, the forecast scenarios based upon this estimated relationship suggest that Turkish aggregate electricity demand will be somewhere between 259 and 368 TWh in 2020 and it is argued that these are likely to be more reliable than previous forecasts, which on the whole suggest higher demand. 


\section{References}

[1] International Energy Agency (IEA). Energy Balances for OECD Countries. Retrieved on 20 September 2010 from

http://esdsw1.mc.manchester.ac.uk/WDS_IEA/TableViewer/tableView.aspx?ReportId=960.

[2] Kaya D. Renewable Energy Policies in Turkey. Renewable and Sustainable Energy Reviews 2006; 10: 152-163.

[3] Ediger VS, Tatlidil H. Forecasting the primary energy demand in Turkey and analysis of cyclic patterns. Energy Conversion and Management 2002; 43: 473-487.

[4] Turkish Electricity Transmission Co. 2009. Turkish Electricity Generation Capacity Projections 2009-2018 (in Turkish translated by authors) (retrieved on 2 April 2011 from http://www.teias.gov.tr/projeksiyon/KAPASITEPROJEKSIYONU2009.pdf).

[5] Keleş SM. Electricity demand forecasts and their effects on Turkish economy. (in Turkish translated by authors) Republic of Turkey Prime Ministry under Secretariat of Treasury Ankara; 2005. Retrieved on 14 March 2009 from

http://www.hazder.org.tr/tezler/Mehmet Sertac_Keles-

Elektrik_Enerjisi_Talep_Tahminleri_ve_Turkiye_Ekonomisine_Etkileri.pdf

[6] Bakirtas T, Karbuz S, Bildirici M. An econometric analysis of electricity demand in Turkey. METU Studies in Development 2000; 27/1-2, Middle East Technical University, Ankara Turkey.

[7] Erdogdu E. Electricity Demand analysis using cointegration and ARIMA modelling: A case study of Turkey. Energy Policy 2007; 35: 1129-1146.

[8] Ozturk HK, Ceylan H. Forecasting total and industrial sector electricity demand based on genetic algorithm approach: Turkey case study. International Journal of Energy Research. 2005; 29: 829-840.

[9] Kavaklioglu K, Ceylan H, Ozturk HK, Canyurt OE. Modelling and prediction of Turkey’s electricity consumption using artificial neural networks. Energy Conservation and Management 2009; 50: 2719-2727.

[10] Hamzacebi C. Forecasting of Turkey's net electricity consumption on sectoral bases. Energy Policy 2007; 35: 2009-2016. 
[11] Akay D, Atak M.Grey prediction with rolling mechanism for electricity demand forecasting of Turkey. Energy 2006; 32: 1670-1675.

[12] Harvey AC. Forecasting, Structural Time Series Models and the Kalman Filter. Cambridge University Press: Cambridge; 1989.

[13] Hunt LC, Judge G, Ninomiya Y. Modelling Technical Progress: An Application of the Stochastic Trend Model to UK Energy Demand. Surrey Energy Economics Discussion Paper, Surrey Energy Economics Centre (SEEC), Department of Economics, University of Surrey, Guildford, UK 2000; SEEDS99.

[14] Kalman RE. A New approach to Linear Filtering and Prediction Problems. Journal of Basic Engineering 1960; 82: 35-45.

[15] Doornat V, Koopman SJ, Ooms M, Dessertaine A, Collet J. An hourly periodic state space model for modelling French national electricity load. International Journal of Forecasting 2008; $24: 566-587$.

[16] Harvey AC, Koopman SJ. Forecasting hourly electricity demand using time varying splines. Journal of American Statistical Association 1993; 88-424: 1228-1236.

[17] Hunt LC, Ninomiya Y. Unravelling Trends and Seasonality: A structural Time Series Analysis of Transport Oil Demand in the UK and Japan. The Energy Journal 2003; 24-3: 6369.

[18] Hunt LC, Judge G, Ninomiya Y.Modelling Underlying Energy Demand Trends. Chapter 9 in Hunt, L.C. (Ed) Energy in Competitive Market: Essays in Honour of Colin Robinson. Edward Elgar, UK; 2003:140-174.

[19] Hunt LC, Judge G, Ninomiya Y. Underlying trends and seasonality in UK energy demand: a sectoral analysis. Energy Economics 2003; 25: 93-118.

[20] Dimitropoulos J, Hunt LC, Judge G.Estimating Underlying Energy Demand Trends using UK Annual Data. Applied Economics Letters 2005; 12 : 239-244.

[21] Amarawickma HA, Hunt LC. Electricity Demand for Sri Lanka: A Time Series Analysis. Energy 2008; 33: 724-739. 
[22] Dilaver Z, Hunt LC. Industrial Electricity for Turkey: A Structural Time Series Analysis. Energy Economics 2011, 33: 426-436.

[23] Dilaver Z, Hunt LC. Modelling and Forecasting Turkish Residential Electricity Demand Energy Policy (In Press) (doi:10.1016/j.enpol.2011.02.59)

[24] Harvey AC, Koopman SJ. Diagnostic checking of unobserved-components time series models. Journal of Business \& Economic Statistics 1992; 10: 377-389.

[25] Koopman SJ, Harvey AC, Doornik JA, Shephard N. STAMP Version 8 Econometric Software International Timberlake Consultants, London, 2007.

[26] World Bank .World Development Indicators; 2010. Retrieved on 20 September 2010 from

http://esdsw1.mc.manchester.ac.uk/WDS_WB/TableViewer/dimView.aspx?ReportId=43.

[27] Altas M, Fikret H., Celebi E.6th Turkish energy Congress, Energy Statistics. 17-22 October 1994, Izmir, Turkey (in Turkish translated by authors).

[28] Taymaz E, Yilmaz K. Integration with the global economy the case of Turkish Automobile and consumer electronics Industries. Commission on Growth and Development Workshop 12-14 April 2007 Washington; retrieved on 22 March 2009 from http://www.ku.edu.tr/ku/images/EAF/eaf wp 0801.pdf

[29] Ediger V, Akar S. ARIMA forecasting of primary energy demand by fuel in Turkey. Energy Policy 2007; 35: 1701-1708. 

Note:

This paper may not be quoted or reproduced without permission

Surrey Energy Economics Centre (SEEC) Department of Economics University of Surrey

Guildford Surrey GU2 7XH 
SuRReY

ENERGY $_{\text {Net }}$

Economics

Discussion paper

$\mathbf{S}_{\text {ERIES }}$

\title{
For further information about SEEC please go to:
}

\author{
www.seec.surrey.ac.uk
}

